\title{
Some Conditions for More Perceivable Landscape Aesthetics Manifestation
}

\author{
Emil Galev ${ }^{1 *}$, Anna Hourani ${ }^{1}$ and Fedir Markov ${ }^{2}$ \\ ${ }^{1}$ Faculty of Ecology and Landscape Architecture, University of Forestry, Bulgaria \\ ${ }^{2}$ Faculty of Forestry and Ecology, Polissya National University, Ukraine
}

*Corresponding author: Emil Galev, Faculty of Ecology and Landscape Architecture, University of Forestry; 10 Kliment Ohridski Blvd., 1797 Sofia, Bulgaria

\begin{abstract}
ARTICLE INFO
Received: 幽 March 06, 2021

Published: 唪 March 16, 2021

Citation: Emil Galev, Anna Hourani, Fedir Markov. A Case Report on Lower Self-Esteem Issues Among Black American Men in Relation to their Dark Skin Color and Homosexuality. Biomed J Sci \& Tech Res 34(4)-2021. BJSTR. MS.ID.005576.
\end{abstract}

Keywords: Accent Group of Trees; Open Spaces; Rivers and Water Bodies; Scenic Beauty; Tree Plantations; Visual Attractiveness

\begin{abstract}
This article illustrates several specific composition techniques that will improve visual attractiveness of forest landscapes located along rivers and other water bodies and streams. There are presented some results of the analysis of visual characteristics and spatial design of the open spaces and tree plantations in these riparian landscapes. Different situations are considered in terms of the size and shape of the water component of the landscape, and the relief features of the site, and the characteristics of the vegetative cover, etc. This study may help to clarify many issues on the design of ecotrails, and to establish criteria and standards for their construction and their maintenance responsibilities. There are several guidelines we can use to help improve the scenic aesthetic composition refers to the way the various elements in a scene are placed and proportionate. Landscape aesthetic and visual quality can be achieved by some practical tips which have come from such analyzes over time, that study and establish what in general made people focus on landscape beauty. In most cases, this can be an emphasis group of trees, even a single tree. It can also be an architectural element such as a bridge, barrage, or other hydraulic structure. But ultimately the overall composition plays a major role in the scenery aesthetics. The routes planning decision and the overall plant composition are crucial in all situations, with details and highlights in the background.
\end{abstract}

The theory and practice of the sensuous cognition of landscape qualities is an endless field of research, and any new study like this hope to add a little more to the landscape architect's knowledge and experience on this difficult and complex issue.

\section{Introduction}

At present, the applied significance of such research is very well proven in the activities in spatial planning and design, tourism and in general in all spheres of modern life Gurkova [1]. Bulgarian tourists and nature lovers themselves have created some remarkable ecotrails, surrounded by beautiful scenery of mountains, waterfalls, forests, cliffs, and gorges. Landscape architects here are debtors of the society in this regard remain static observers of tourism issues. There are, however, several guidelines we can use to help improve the scenic aesthetic composition refers to the way the various elements in a scene are placed and proportionate. Open spaces along the rivers and lakes provide the best opportunities for visual perceptions of landscapes from tourists and analyses of riparian landscapes from landscape architect's point of view. Therefore, most of the research on the aesthetics of riparian landscapes so far has been focused on the open spaces along rivers and lakes. There, the field of surveillance is the most spacious and gives a good choice of perspective. Since each level of monitoring, we have a different horizon and a different distance to a pictorial plane. This determines as important different plans in space examined in great detail in Bell [2] and in Minghua, et al. [3]. It is very difficult to be summarized and systematized all scientific views on the issue of forest landscape perceptions and especially of scenic beauty.

Here are researched and investigated several models of scenic quality Thomas $[4,5]$ that are based on combining parts of reconstructive methods, park perspective, spatial composition, and painting techniques of imagery. They can make design process 
much easier and the resulting landscape 'picture' - applicable to planning process, respective to landscape design. Such a sufficiently simple, fast, and effective could be called the park design guidelines published in Kosarevskiy [6]. Although visual complexity and aesthetic quality are stretchable concepts the whole picture of a perfect landscape comes from the well thought out and successful park design drawing and is responsible of the subsequent realization in real space. That is why the landscape planning itself as a pictorial space is essential for the panoramic view recovery. The theoretical considerations regarding studied in this paper problems are influenced by similar publications in ecology, especially in McCormack [7] and in Van Oosten, et al. [8], which proposed that increasing ecological diversity is correlated with increasing stability, and hence with environmental quality. Other researchers Watts $[9,10]$ have explicitly linked these two ideas, proposing that ecologically stable, i.e., healthy, landscapes are intrinsically beautiful.

This paper takes one of these relationships, that between visual complexity and perceived scenic quality, here termed scenic beauty, for further investigation. To focus properly on ways to enhancing the riparian forest and meadow landscape aesthetics and to understand public perception of scenic beauty we also studied many methodologies that has often been applied to evaluate forest scenic beauty Schroeder [11-13]. It is always difficult and very relative to postulate the principles of the aesthetic qualities of the landscapes and, in particular, the riparian forest and meadow landscapes. It is even more difficult to typify human perceptions of landscape attractiveness. As the present study precisely addresses such aspects, the findings of scientific articles such as SAEFL, et al.
[14-16] are considered. The main objective of the study is to define some principles of landscape design the implementation of which would improve the aesthetic qualities and the visual attractiveness of riparian forest and meadow landscapes.

\section{Material and Methods}

This paper is based on the long-term multiannual observation, in order to determine what most impresses people walking or resting along rivers, lakes and other water bodies. The objects we observe are extremely many, but only two of them (Figure 1) have been selected as the objects of research in this article, and they are the ones that combine most of the positive characteristics of the riparian forest and meadow landscapes. The first of them is the Veleka River and its coastal terrains along its lower course and at its confluence with the Black Sea at geographical coordinates: $42^{\circ} 04^{\prime} 13^{\prime \prime} \mathrm{N} ; 2^{\circ} 58^{\prime} 08^{\prime \prime} \mathrm{E}$, and elevation $0 \mathrm{~m}$ above sea level. The second object of research is Dospat Dam and its coastal lands at

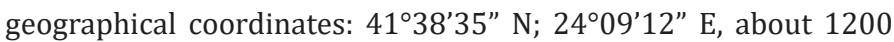
$\mathrm{m}$ a.s.l. It is among the largest dams in Bulgaria in terms of area and water volume. Before accepting any project concept, we got acquainted with many other scientific researches in this field. Several methods were used to determine the aesthetical aspects of the selected objects of research. Referring to the methodologies applied in the cited sources, optical and other sensory effects of the riparian forest and meadow landscapes was analysed. The main method used in the present study is the field observation and survey (expedition method), which is used to get acquainted with the actual situation and a set of information through route (cognitive) traversal of the terrain and conducting field landscape research.

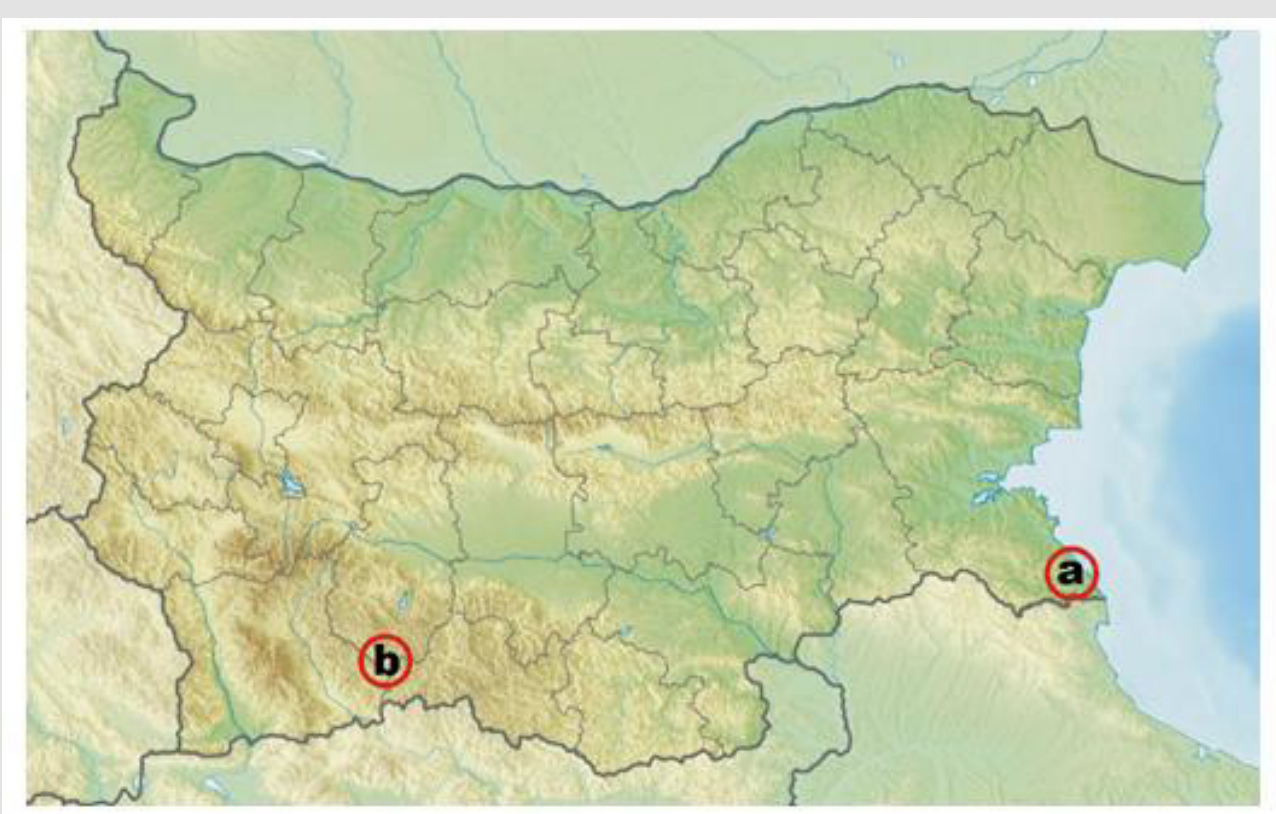

Figure 1: The objects of research in this article:

a) Coastal terrains along lower course of the Veleka River and its confluence with the Black Sea;

b) The Dospat Dam and its coastal lands. 
The method of graphoanalytical analysis is applied to summarize the results of the derived graphic information obtained when working with the source data, and in combination with the method of parallel superposition (superposition) - in the synthesis and creation of the typology of landscapes. The expert method (method of critical analysis and expert evaluation) is used to interpret photographic information. The main approach used in the present study is the geo ecological (landscape-ecological), in which the emphasis is mainly on the analysis of environmental conditions and their differentiating role in the landscape, as environmental factors include not only abiotic (geomatic) components. of the landscape sphere, but also the biota - both as part of the environment and as a biological focus of the landscape. Its application requires a study of the role and significance of the various landscape components, but first of all - the geomatic ones. The multiplication approach has found application in considering the interaction between all studied factors and their multifaceted reflection in the results of development for the whole territory.

\section{Results and Discussion}

Aesthetic feelings are by their nature specific human experiences, caused by the perception of the beautiful and the ugly, of the comic and the tragic in reality. Since the predominant part of human perceptions in the natural environment are visual, in any case, in order to express the positive aesthetic qualities of a certain natural object, visibility to it must first be ensured. This also applies to riparian and coastal landscapes in general, so the first condition for increasing the aesthetics in these landscapes is that they be visible as much as possible. This can be achieved if the principle of maximum proximity of the routes of the coastal alleys to the banks of the watercourse is applied in the planned composition of the alley network (Figure 2). Of course, this is not always possible and depends on the terrain. However, where possible, it is advisable to design coastal alleys as close as possible to the watercourse and to cross it quite often (Figures 2a-2c), at least the secondary alleys (Figure 2d). This increases the attractiveness of the route itself, with the appearance of picturesque panoramic views of watercourses and water surfaces (Figure 3). In order to express the aesthetics of the riparian landscapes, the vegetation is of great importance. However, it should not obscure, but direct the gaze to the water currents and water areas, to focus attention on the beautiful accents in the riparian landscapes.

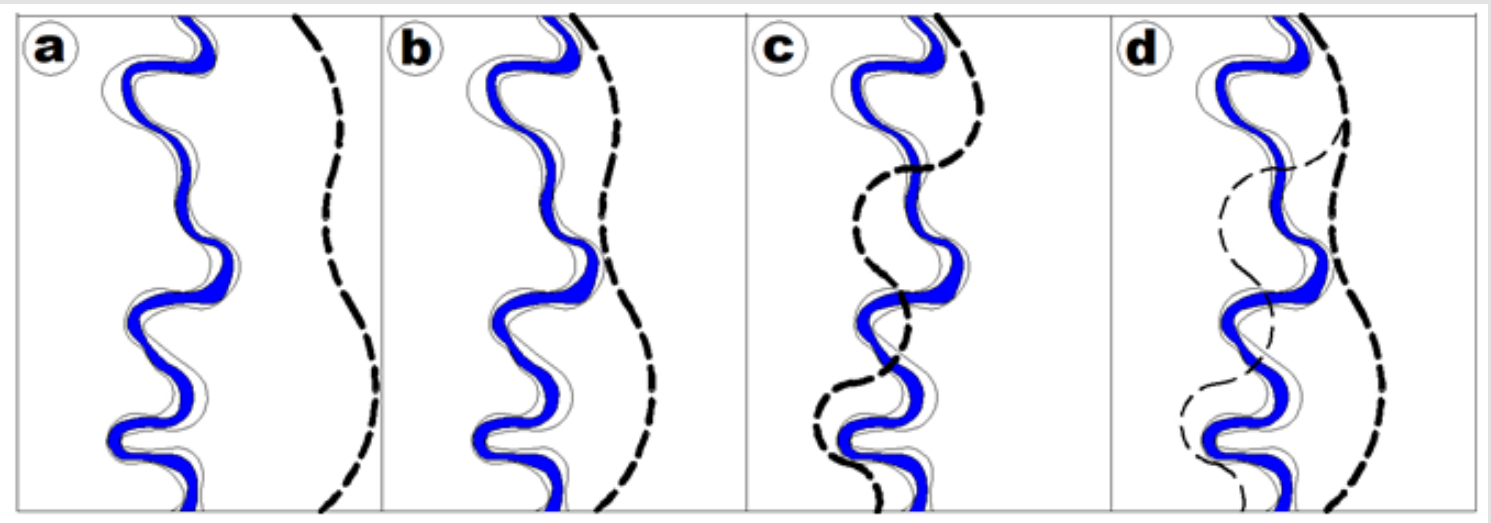

Figure 2: Recommended walking route layout relative to the river bed:

a) The walking route passes far from the riverbed;

b) The walking route passes near the riverbed without crossing it;

c) The walking route passes near the riverbed and crosses it;

d) The main walking route passes near the riverbed, and a secondary duplicate route cross it.

(Figure 3a) illustrates quite schematically the cases in which the vegetation obstructs the view, and (Figure $3 \mathrm{~b}$ ) shows the general configuration of the plant volumes, in which they have a positive effect on the aesthetic qualities of the landscapes along rivers and lakes. Excessively dense vegetation interferes much more with visibility, especially on sloping terrain, which is also shown in (Figure 4). In such terrain conditions, it is especially necessary to create visual 'corridors' or visual 'frames' composing the vegetation in the form of groups, between which the gaze passes into the background of the visual perspective. When the route of the pedestrian paths moves away from the watercourses, the visibility to them decreases, and the observer has a wider visual range to the surrounding landscapes from a higher point (Figure 5a). The main reason for this is the vegetation that obstructs the view in the lower parts of the terrain (Figure 5b). Of course, it cannot be removed from there because this will lead to erosion processes. In such cases, it is much more difficult to provide visual 'corridors', but they create deeper visual perspectives. Most often, some infrastructure facilities are used for this purpose and viewpoints are organized near them (Figure 6). Various infrastructural facilities almost always pass through the river valleys and the main problem that arises before the spatial planning is where exactly to situate them, so as not to disturb the ecology and aesthetics in the riparian landscapes. 


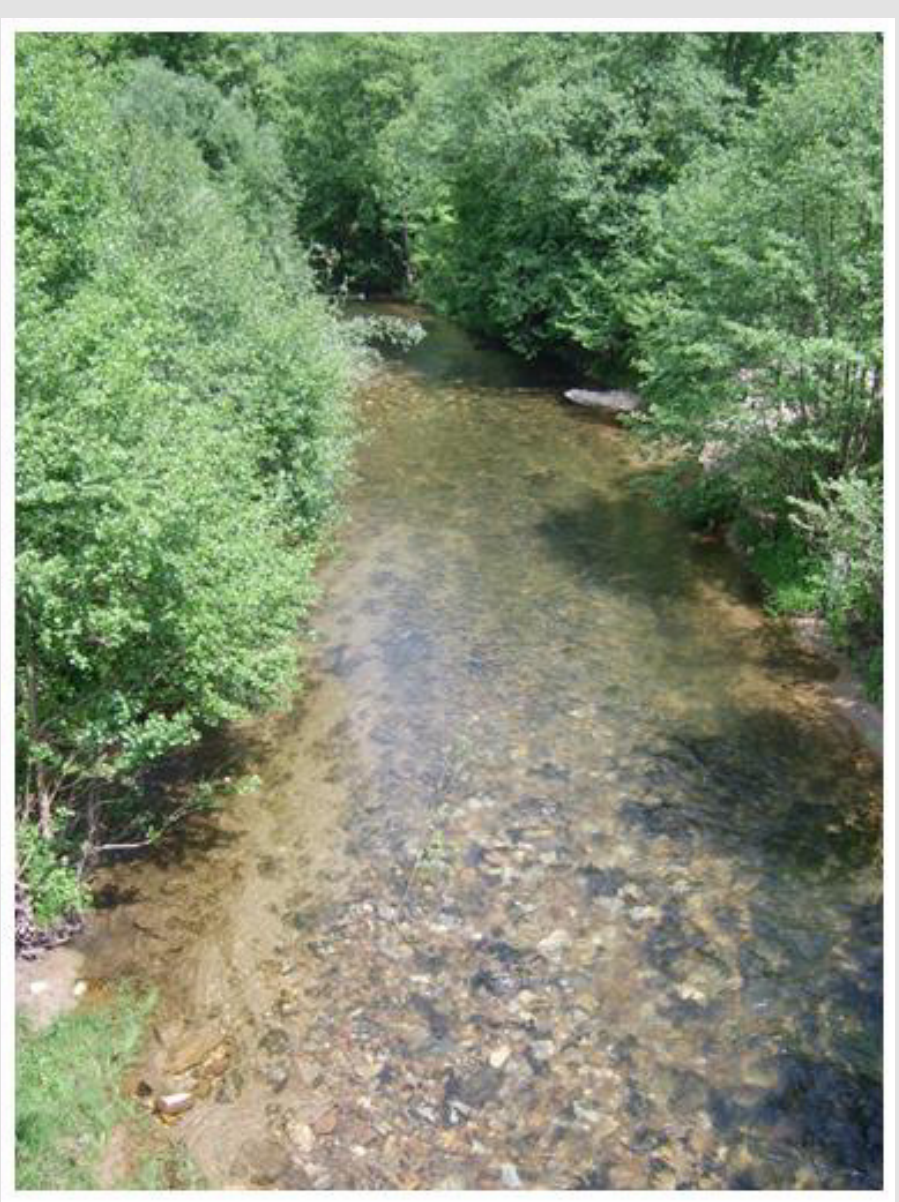

Figure 3: The views from above to rivers and water surfaces reveal to the greatest extent the beauty of nature (view from a cable-stayed bridge to the waters of the Veleka River).

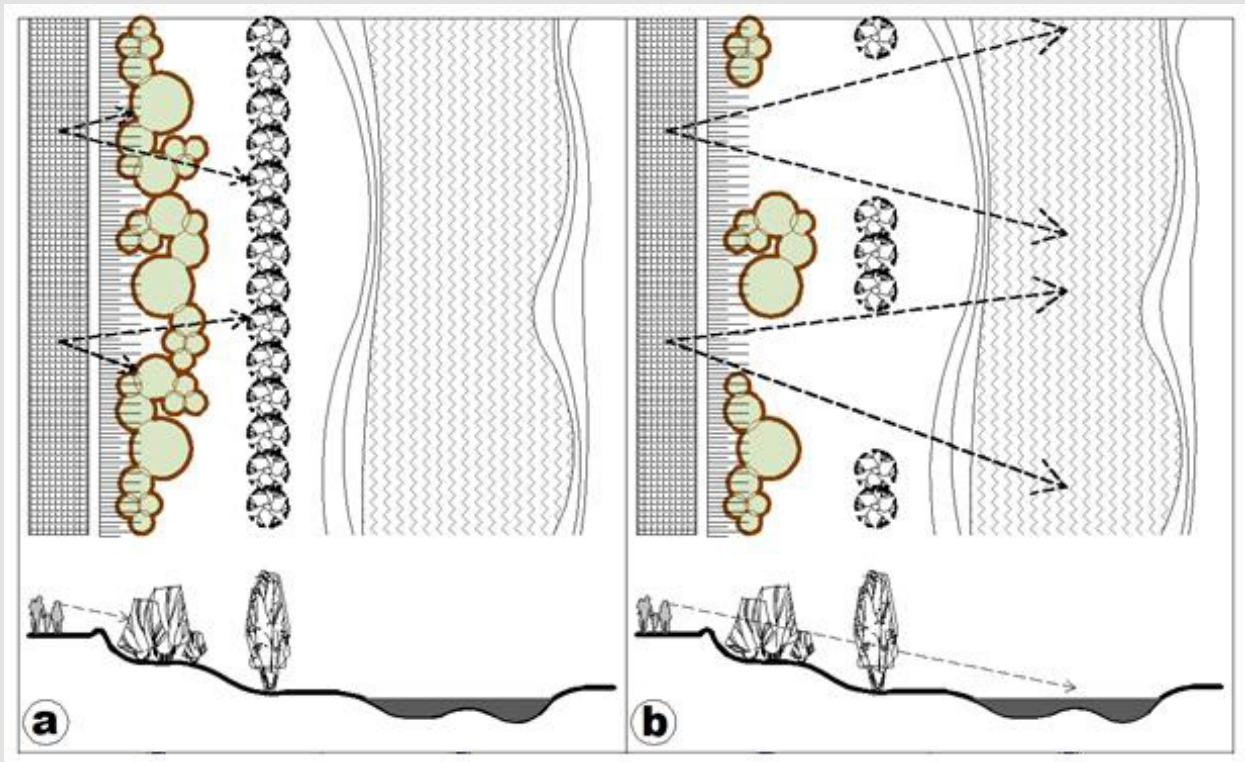

Figure 4: Interfering

(a) and favourable

(b) Spatial composition of the vegetation from the point of view of the aesthetics of the landscape. 


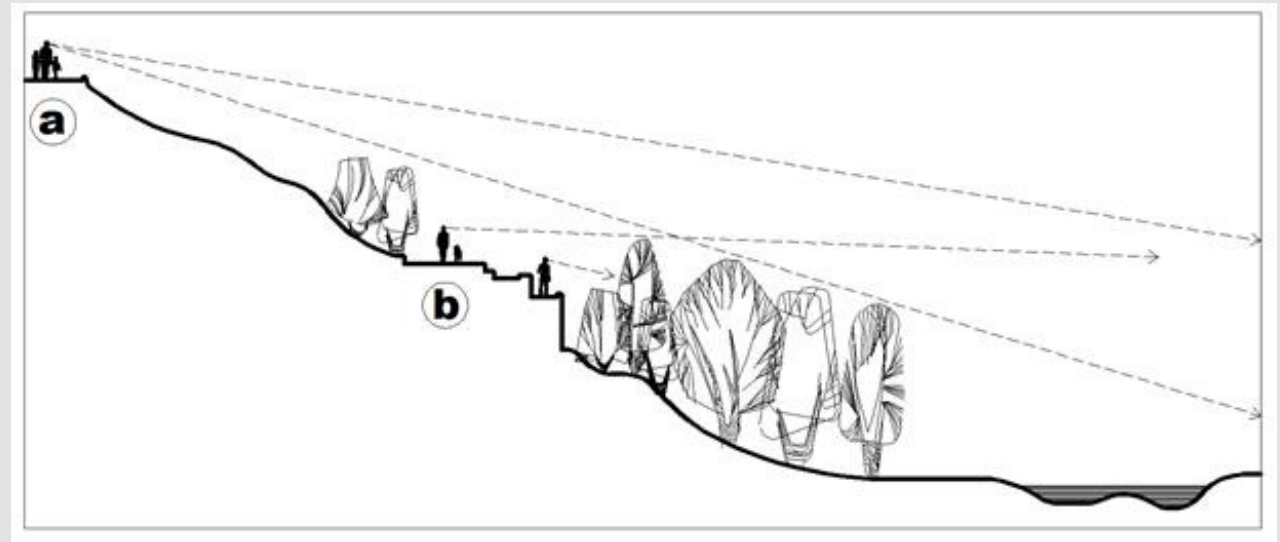

Figure 5: Increasing reduction of visual contact with watercourses and surfaces when moving pedestrian paths away from them, even in the presence of displacement.

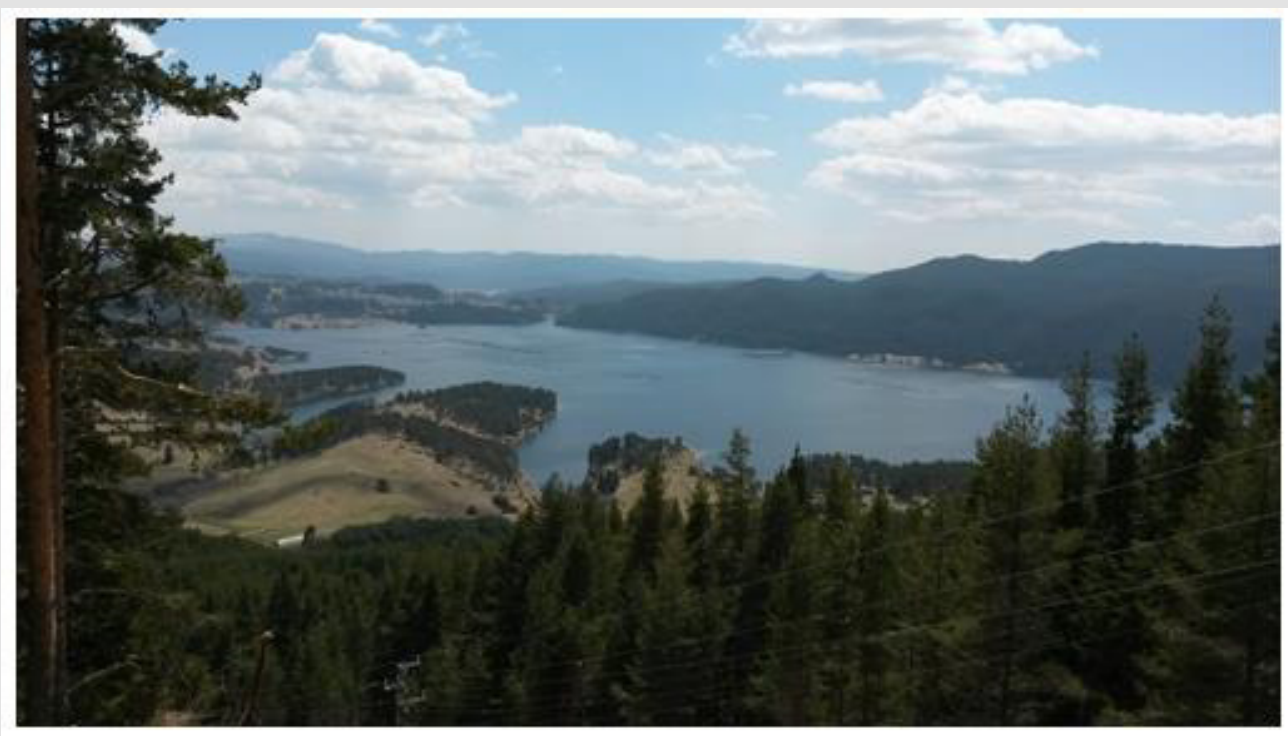

Figure 6: Visual corridor to a landscape fragment of a water surface, thanks to a forest clearing for a power line (panoramic view from a forest clearing to the Dospat Dam).

In the case of a wide river valley (Figure $7 \mathrm{a}$ ), the roads and infrastructure facilities are laid out along the outlines of the lowland part, joining the slopes and edges of the forests, and the river remains free with landscaping and possibly pedestrian connections along it. In a narrow river valley and more sparse forest cover (Figure 7b), roads and infrastructure facilities are situated above the surrounding slopes and are 'sheltered' behind the edges of the forests that cover the slopes. In the case of a narrow river valley and a compact forest cover, the roads and infrastructure facilities may be connected to the river (Figure 7c) or may completely liberate the valley for the construction of paths and places for visitors in the riparian areas and be held along the ridges (Figure $7 \mathrm{~d}$ ), impose more rudely in the appearance of the natural environment, but on the other hand they will reveal more extensive panoramic landscape views. Among all landscape components woody vegetation to the greatest extent plays the strongest role in shaping the visual perspective views. These views are internal when the visibility is within the meadow or external when the visibility goes beyond the open space where the observer is. In settling of riparian landscapes as recreation environment is very important to position correctly points of accents. In the example in (Figure 8) is defined properly the place in the bend of the river as a focus on composition. 


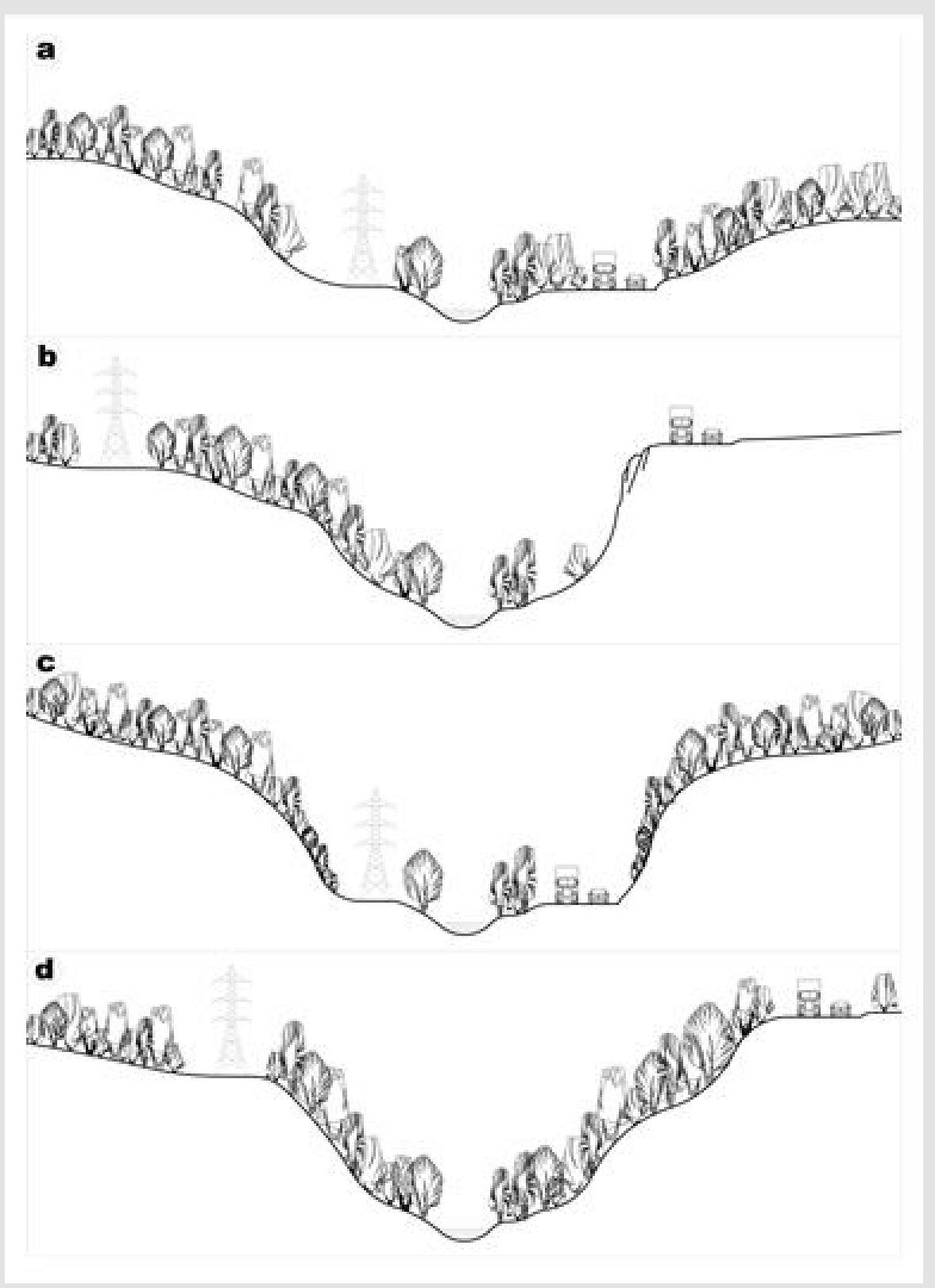

Figure 7: Schematic diagrams for the location of the forest cover in the cross section of a valley:

a) A wide river valley where the roads and infrastructure facilities are laid out along the outlines of the lowland part;

b) A narrow river valley and more sparse forest cover, where roads and infrastructure facilities are situated above the surrounding slopes;

c) A narrow river valley and a compact forest cover, where the roads and infrastructure facilities are connected to the river;

d) A narrow river valley and a compact forest cover, where the roads and infrastructure facilities are completely liberate the valley for the construction of paths and places for visitors in the riparian areas, and be held along the ridges.

There are several secondary accent groups of trees and are also designed several internal linear perspectives along the promenade. A great pursuit of every designer is in creating multilayered landscape views. These views are the biggest 'prize' for tourists after many time transitions. The creation and maintenance need proper stewardship of forest vegetation which causes the eyes to focus, but also close the beautiful panoramic views. These favorable aesthetic effects are achieved also in the spatial design of the coastal promenade in (Figure 9). There have even made deep and external linear perspectives to the opposite shores of the water area. The volumetric-spatial solution of the zones around water areas is reduced to the following: 


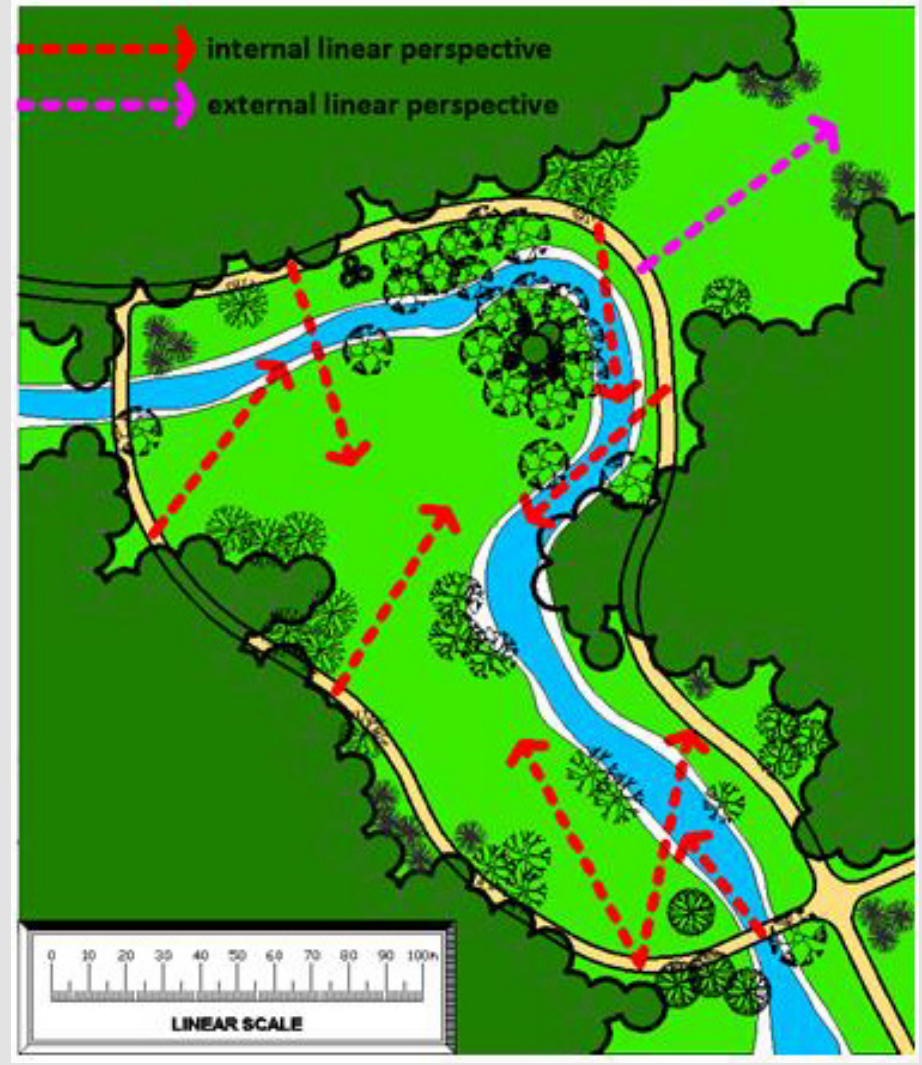

Figure 8: A landscape design project for space planning along a walking trail parallel to a stream.

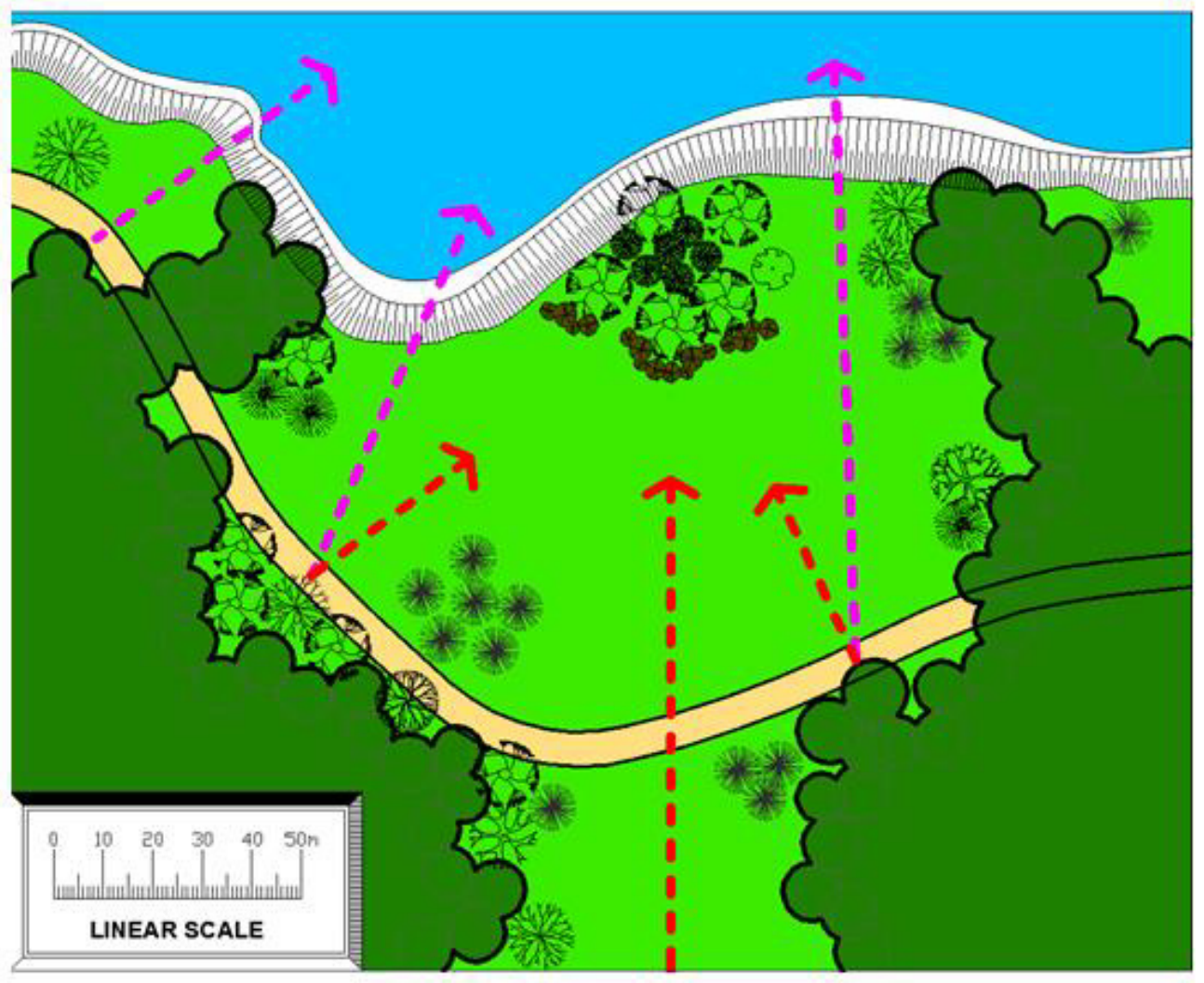

Figure 9: A landscape design project for space planning along a coastal walking trail near the shore of a water area. 
a. Creation of open spaces (beaches with public service establishments, piers and viewing platforms) on the southfacing shores (Figure 10),

b. Close approach of the wood-bush massifs to the water along the shore with northern exposure - the impact of the cast shadows and the reflection of the plant volumes on the water surface (Figures $10 \& 11$ ) is taken into account, which gives greater picturesqueness and dynamics of the coastline,

c. Construction of semi-open spaces from east and west

- through openwork decorative tree-shrub groups and tapeworms to achieve greater plasticity of the spaces, through natural daylight and modeling an interesting play of light and shade throughout the day (Figure 10).

In all possible cases, when designing the routes of tourist routes, the property of the water to reflect the surrounding plant, architectural or sculptural volumes must be used (Figure 11). When including calm water surfaces (lakes, pools, water mirrors, etc.) in the general compositional solution of the nature parks, their favorable influence on the psycho-physical condition of the person and for the rest of the eyes is relied upon.

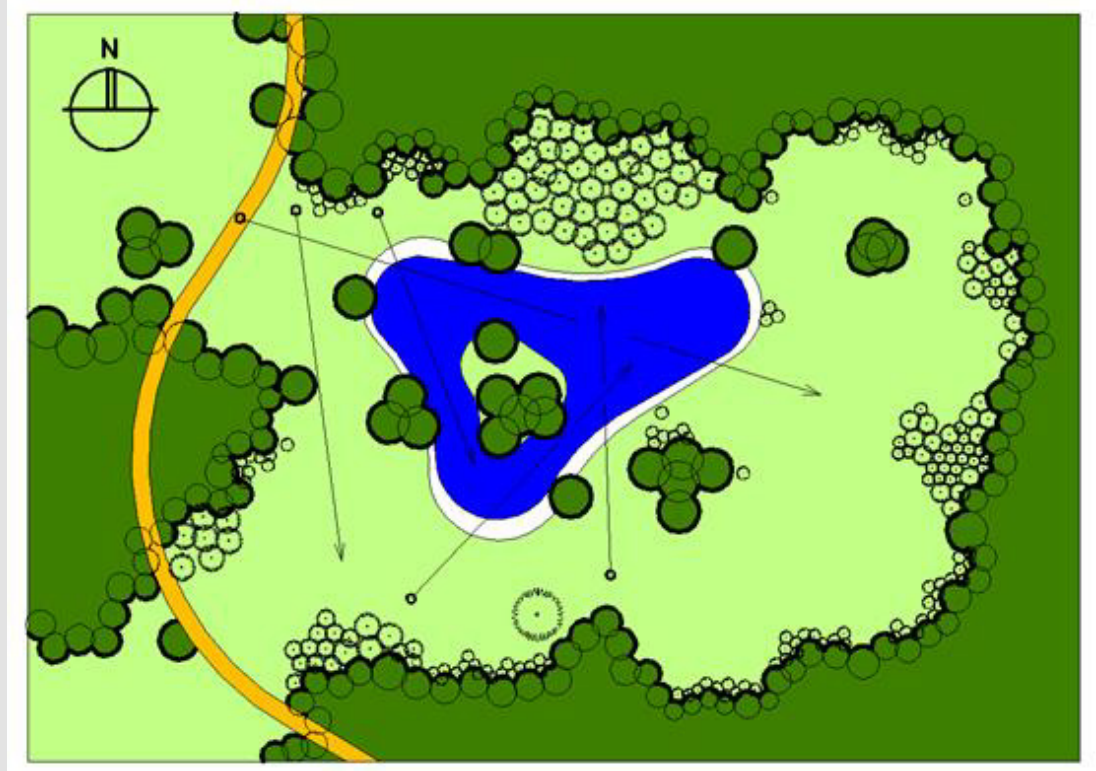

Figure 10: Forming the shores of a water area with vegetation - compaction of vegetation on the northern shores; 'stripping' of the eastern and southern shores; thinning of the west coasts.

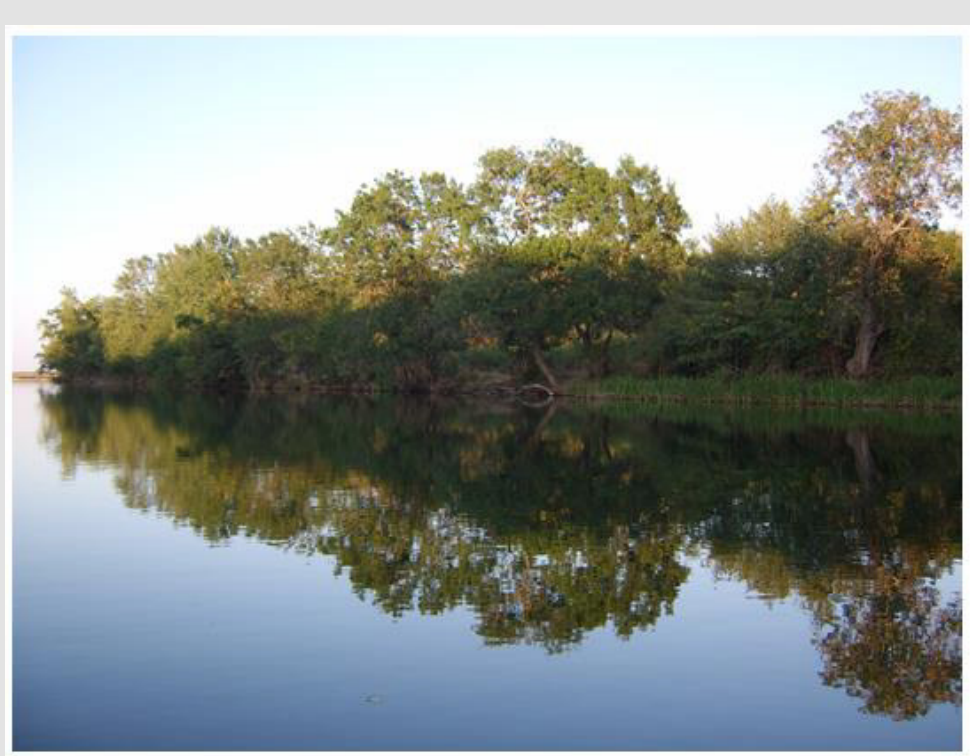

Figure 11: In addition to the principle that the alley should run as close to the water as possible and cross the watercourse as often as possible, alleys should be laid where there are conditions to observe reflections in the water (view from a cable-stayed bridge to the waters of the Veleka River just before its confluence with the Black Sea). 


\section{Conclusion}

According to the performed landscape-ecological study carried out on the riparian forest and meadow landscapes, one reaches the various riches of this landscapes, often hidden or devalued due to their improper exposure to tourists. The problematic was: how to design the routes of hiking trails, that these unique landscapes become not only optically visible but also physically accessible to humans. More generally, this will enhance the benefits of humannature communication. The hypothesis of creating a linear walk along the rivers and water bodies was validated. It is very difficult to summarize all visual situations that predispose dynamic and static observation but given the rich practical experience in the field of landscape architecture we can subtract some general principles or more precisely requirements for forest landscape design along riparian forest and meadow landscapes. These requirements generally relate to the design decision of volumespatial composition of the vegetation and to a lesser extent to the terrain modeling.

As the most common such a requirement may be indicated the necessity of compositional design solution and natural conditions consideration. Accordance with the most significant landscape components (relief, rock formations, lakes, rivers, streams, vegetation, etc.) always is a leading factor that ensures an adequate design solution. Complying a rate in accent saturation is very important aesthetic rule in the landscape design along rivers and around water surfaces. Each aesthetic natural picture requires a correct accent dosage. This is particularly important in riparian landscapes, to preserve their natural appearance and charm.

\section{References}

1. Gurkova M (2015) Features of development intervention needs of cultural tourism in forest areas. Journal of Management and Sustainable Development, University of Forestry, Sofia, Bulgaria 55: 91-96.

2. Bell S (2004) Elements of Visual Design in the Landscape. (2 ${ }^{\text {nd }}$ Edn.). Spon Press, London and New York, USA, pp. 220.

ISSN: 2574-1241

DOI: 10.26717/BJSTR.2021.34.005576

Emil Galev. Biomed J Sci \& Tech Res

This work is licensed under Creative Commons Attribution 4.0 License

Submission Link: https://biomedres.us/submit-manuscript.php
3. Minghua H, Mo C, Xiaonan S (2009) The Construction of Landscape Pattern at Comprehensive Planning Level in Northwestern China-a Case Study of Ankang City. In: The $4^{\text {th }}$ International Conference of the International Forum on Urbanism (IFoU). Amsterdam/Delft. The New Urban Question - Urbanism beyond Neo-Liberalism. pp. 819-827.

4. Thomas CB, Terry CD (1991) Landscape Aesthetics of Riparian Environments: Relationship of Flow Quantity to Scenic Quality Along a Wild and Scenic River. Water Resources Research 27(8): 1787-1795.

5. Stoycheva M (2016) A Spatial Method in the Park Design. PhD thesis, University of Forestry, Sofia, Bulgaria pp. 108.

6. Kosarevskiy IA (1977) The art of landscaping. Stroyizdat, Moscow, Russia pp. 246.

7. Mc Cormack A, O'Leary T (2000) Forestry and the Landscape Guidelines. Published by the Forest Service, Department of the Marine and Natural Resources in Dublin, Ireland, p. 16.

8. Van Oosten C, Gunarso P, Koesoetjahjo I, Wiersum F (2014) Governing Forest Landscape Restoration: Cases from Indonesia. Forests 5: 11431162.

9. Watts S, Tolland L (2005) Visual resources and forest management. In: The Forestry Handbook for British Columbia. Faculty of Forestry, University of British Columbia, Forest Sciences Centre, Vancouver, Canada pp. 700 .

10. (2011) Forestry Commision. Forests and Landscape. UK Forestry Standard Guidelines. Edinburgh p. 80.

11. Schroeder HW, Daniel TC (1981) Progress in predicting the perceived scenic beauty of forest landscapes. Forest Science 27: 71-80.

12. Buhyoff GJ, Wellman JD, Daniel TC (1982) Predicting scenic quality for mountain pine beetle and western spruce budworm damage forest vistas. Forest Science 28(4): 827-838.

13. Ribe RG (1990) A general model for understanding the perception of scenic beauty in Northern hardwood forests. University of Wisconsin Press. Landscape Journal 9(2): 86-101.

14. (2003) SAEFL (Swiss Agency for the Environment, Forests and Landscape). Landscape 2020 - Guiding Principles. In: Berne Stremlow M, Pfiste H (Eds.).). p. 20

15. Lovell ST, Johnston DM (2009) Designing landscapes for performance based on emerging principles in landscape ecology. Ecology and Society 14(1): 24 .

16. Lee Hsueh L (2018) Ecological Aesthetics: Design Thinking to Landscape Beauty with Healthy Ecology. Chapter 5: 89-104.

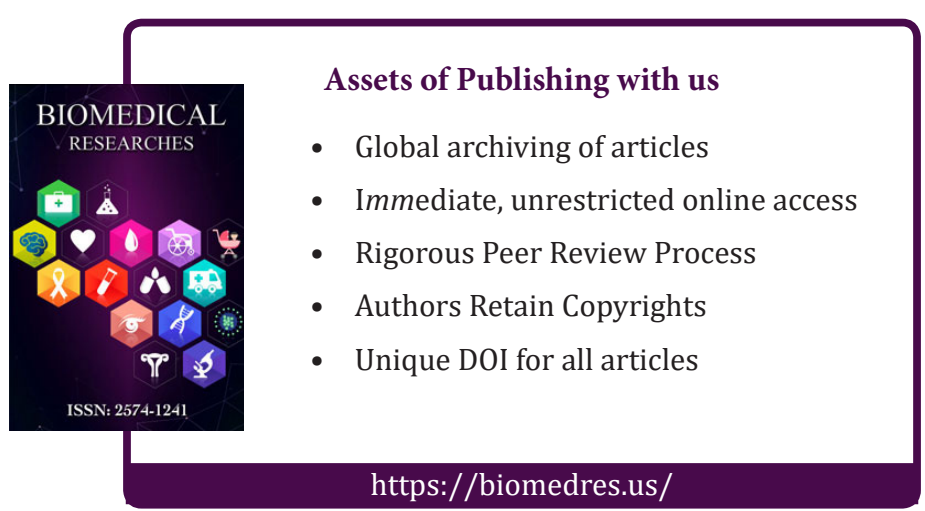

